\title{
High-dosage short-term corticotrophin therapy in acute asthma
}

\author{
I. W. GLICK ${ }^{1}$ A N D M. FRIED M A N \\ From the Brompton Hospital and Paediatric Department, University College Hospital, and \\ Clinical Research Centre, London
}

\begin{abstract}
The effect of corticotrophin suspended in gelatin in doses varying from 40 to 400 i.u. on the plasma 11-hydroxycorticosteroid response has been investigated in volunteer subjects in order to determine the optimum dose required to produce prolonged and continuous adrenocortical stimulation using this preparation. Increasing the dose of corticotrophin beyond 200 i.u. did not produce a greater intensity or prolongation of adrenocortical stimulation; $300 \mathrm{i}$.u. corticotrophin in $7.5 \mathrm{ml}$. of gelatin produced the same effect as $310 \mathrm{i} . \mathrm{u}$. in $1 \mathrm{ml}$. gelatin. In order to achieve prolonged and continuous adrenal stimulation the optimum dose of corticotrophin would appear to be 200 i.u., which could be suspended in $1 \mathrm{ml}$. of gelatin for ease of administration, and which produced adrenal stimulation for approximately 36 hours. The effect of the administration of a single large dose of corticotrophin has been investigated in 13 asthmatic patients during an exacerbation. All had failed to respond to conventional therapy but responded to corticotrophin with one exception. Five patients required no more than two injections for a sustained remission. Seven were discharged needing prolonged corticotrophin in conventional doses. The advatage of using this form of corticotrophin therapy over a short course of high-dosage corticosteroid therapy is discussed.
\end{abstract}

The administration of corticosteroids for prolonged periods of time to patients with asthma may be hazardous because of the side-effects (Nabarro, 1960). Many patients are started on what is intended to be a course of corticosteroids during an acute exacerbation of asthma. When attempts are made to stop the steroids there may be opposition from those patients whose therapy has relieved their bronchospasm and induced a feeling of well-being. On the other hand, during an acute episode of bronchospasm, which has failed to respond to conventional bronchodilator therapy, relief can sometimes be obtained only by using larger than physiological quantities of adrenal steroids. The alternative to therapy with exogenous steroids such as prednisone, betamethasone or triamcinolone is adrenal stimulation with corticotrophin (ACTH). Since this is administered by injection, it can be withdrawn more easily than oral corticosteroid therapy, with the co-operation of the patient rather than his opposition.

On a number of occasions we have thought that corticotrophin was more effective than corticosteroids in controlling acute exacerbations of bronchospasm when used in high dosage. Some of our patients responded to corticotrophin when they had previously failed to respond to large doses of prednisone. This could be because corticotrophin has many extra-adrenal effects (Engel, 1961) and stimulates the adrenal to produce a large number of different steroids (Farrell and Lamus, 1953) which may affect the underlying pathology.

In this study we have attempted to establish the optimum dose of corticotrophin suspended in gelatin $^{2}$ which will produce prolonged stimulation of the adrenal cortex. Using the data obtained, we have studied a group of adult patients with a severe exacerbation of bronchospasm who had failed to respond to conventional therapy.

\section{METHODS}

ADRENAL RESPONSE TO VARYING AMOUNTS OF CORTICOTROPHIN The effect of adrenocortical stimulation by corticotrophin suspended in gelatin administered by intramuscular injection in varying doses from $40-400$ i.u. was studied in normal subjects. The effect on plasma 11-hydroxycorticosteroid (plasma 11-OHCS)

1Present address: Whipps Cross Hospital, London E.11

${ }^{2}$ Acthar gel: Armour 
levels after 300 i.u. in $7.5 \mathrm{ml}$. of gelatin was compared with that after $310^{3}$ i.u. in $1 \mathrm{ml}$. of gelatin. For purposes of comparison one subject was given 40 i.u. and 300 i.u. of lyophilized corticotrophin. The investigation was carried out on five normal volunteer subjects and one patient with asthma who had received long-term treatment with corticosteroids and then corticotrophin. The subjects continued with their normal activities throughout the investigation. The study was performed without suppression of endogenous corticotrophin production.

At 9.00 hours on the day of the test, each subject was given either $40,80,120,200,300$, or 400 i.u. of corticotrophin preparation ${ }^{4}$ which contained 40 i.u. of corticotrophin suspended in $1 \mathrm{ml}$. of gelatin. The corticatrophin was administered by deep intramuscular injection into the upper outer quadrant of the buttock or the thigh. An interval of at least 10 days and often longer was allowed to elapse between each test. The order of the dose administered to each subject was selected at random. Four subjects were given an injection of a specially prepared batch of corticotrophin containing 310 i.u. in $1 \mathrm{ml}$. of gelatin. One subject was also given 40 and 300 i.u. of lyophilized conticotrophin ${ }^{5}$ by intramuscular injection. Blood samples were taken before and at 1, 3, 5, 7, 9, $12,15,18,21,24,28,32,36,40,42,44$, and 48 hours after the initial injection for measurement of plasma 11-OHCS.

Blood was obtained by venepuncture using heparin as an anticoagulant. The plasma was separated from the cells within 30 minutes and stored at $-20^{\circ} \mathrm{C}$. until the plasma 11-OHCS (cortisol) concentration was measured by a minor modification (Black and Friedman, 1965) of the fluorimetric method (Mattingly, 1962).

ASTHMATIC PATIENTS StUdied The effect of a single large intramuscular dose of corticotrophin was studied in 13 patients with asthma who were admitted to the Brompton Hospital. These patients had all received routine therapy (bronchodilator drugs, antibiotics, and physiotherapy) without remission of the bronchospasm for at least four days before the corticotrophin was given. Each patient was given a single injection of corticotrophin gel. of either $160,200,300$ or 400 i.u. taken from a batch containing 40 i.u. of corticotrophin in $1 \mathrm{ml}$. of gelatin.

The response to the corticotrophin was assessed clinically and by measurement of the peak expiratory flow rates (PEFR) with a Wright Peak Flow Meter at 9 a.m. each morning for three days before the injection. On the day of the injection, the PEFR was measured just prior to the injection and then at $6,12,24,48$, and 72 hours after the administration of the corticotrophin. The quantity of corticotrophin

${ }^{3} \mathrm{~A}$ preparation of approximately 300 i.u. ACTH per ml. was made first and assayed afterwards. It turned out at $310 \mathrm{i} . \mathrm{u} . / \mathrm{ml}$. and hence this stightly unusual strength

${ }^{4}$ Acthar gel batch No. KG 2802

${ }^{5}$ Armour, Batch No. LE. 0309 given was 160 i.u. in one subject, 200 i.u. in seven $\stackrel{\overline{\bar{S}}}{\rightarrow}$ subjects, 300 i.u. in one subject, and 400 i.u. in the remaining four patients. Thirteen asthmatic patients $\frac{\bar{\sigma}}{\mathrm{N}}$ were studied, of whom 11 had not previously received $\overline{\bar{S}}$ steroids or corticotrophin. Two patients had been $\Phi$ given short courses in the past but not within six 20 months prior to the onset of this study. There were $\infty$ seven men and six women of ages ranging between $\overrightarrow{0}$ 18 and 69 years, mean 45 years. All had been asthmatics for from 8 months to 20 years, mean $6.2 \vec{\omega}$ years. Ten patients were classified clinically and on investigation as intrinsic asthmatics, while three had $\vec{x}$ extrinsic asthma.

\section{RESULTS}

ADRENAL RESPONSE TO INTRAMUSCULAR CORTICO- 응 TROPHIN Figure 1 shows the plasma 11-OHCS response obtained with 40 i.u. and 400 i.u. of $\overleftarrow{c}$ corticotrophin in a normal subject. Figure $2 \frac{\bar{\gamma}}{}$ shows the maximum increment (maximum level $\vec{\bullet}$ minus resting level) of plasma 11-OHCS achieved following the administration of increasing quantities of corticotrophin. Figure 3 shows the duration of adrenal stimulation (time taken for plasma 11-OHCS to return to the resting level) following the administration of varying doses of cortico- 을 trophin. The mean maximum increment of plasma 11-OHCS following the injection of 310 i.u. of corticotrophin in $7.5 \mathrm{ml}$. of gelatin was 52.0 (range $58 \cdot 2-75 \cdot 6) \mu \mathrm{g} . / 100 \mathrm{ml}$., while the mean result following 300 i.u. in $1.0 \mathrm{ml}$. of gelatin was 76.4

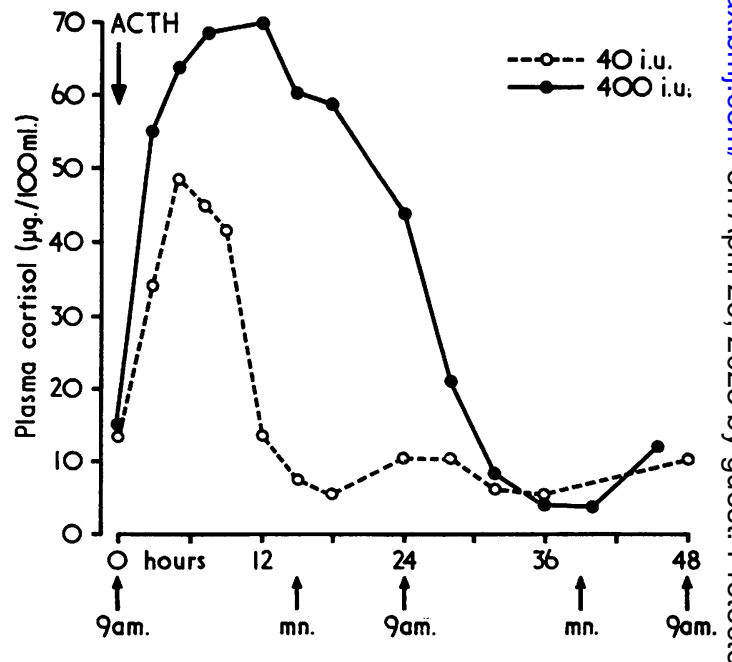

FIG. 1. Plasma 11-OHCS (cortisol) response in $a \stackrel{\Phi}{\circledR}$ normal subject to 40 i.u. and 400 i.u. of corticotrophin in gelatin $(A C T H)$. Note the return of the diurnal rhythm at 0 24 hours after 40 i.u. and at 48 hours after 400 i.lu. 


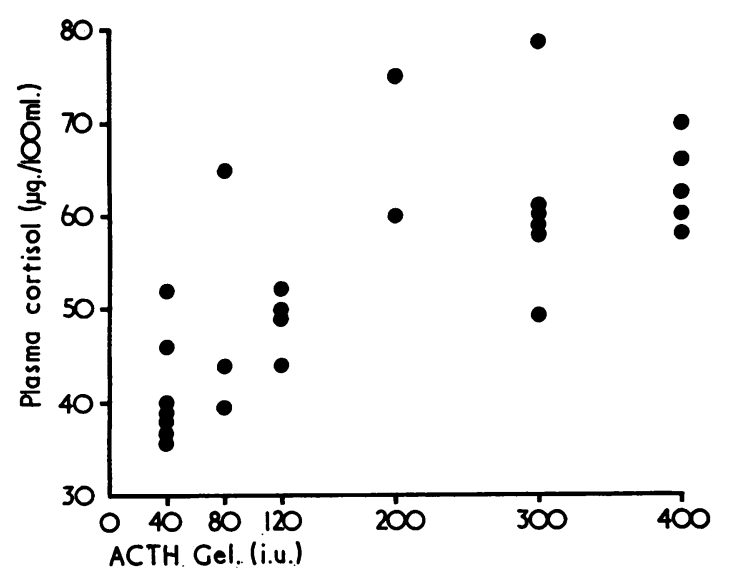

FIG. 2. Maximum plasma 11-OHCS increment (maximum level minus resting level) following increasing doses of corticotrophin in six subjects.

(range 69.4-94.8) $\mu \mathrm{g} . / 100 \mathrm{ml}$. The plasma 11OHCS rise induced by 300 i.u. in 7.5 of gelatin was maintained for up to 48 hours in the five tests performed, whereas the mean duration of elevation of the plasma levels following $310 \mathrm{i}$.u. in 1.0 $\mathrm{ml}$. of gelatin was 30 (range 24-48) hours in the four tests performed at this dosage level. The differences between these two groups are not significant.

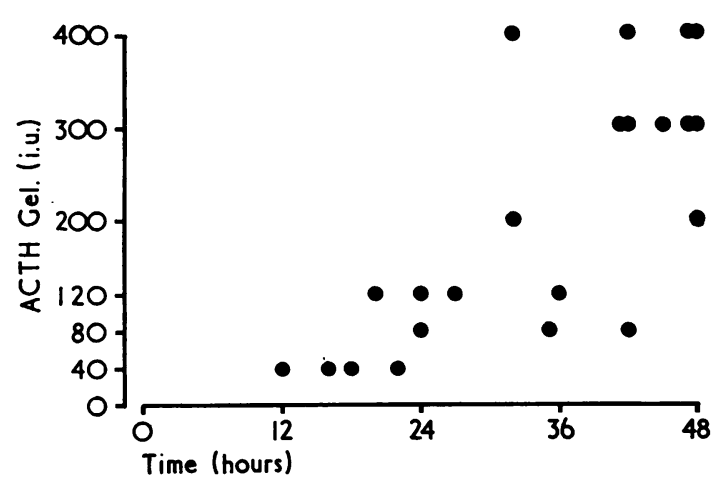

FIG. 3. Duration of adrenal stimulation (time taken for plasma 11-OHCS to return to pre-injection levels) following increasing doses of corticotrophin in gelatin.

Figure 4 shows a comparison of the plasma 11-OHCS response following the administration of 40 and 300 i.u. of corticotrophin in gelatin and the same doses of lyophilized corticotrophin. The injection of gel, even in volumes of up to $10 \mathrm{ml}$., did not produce any adverse reactions or severe discomfort. A slight ache at the site of injection was experienced by most subjects with the larger quantities for up to 12 hours after the injection.

RESPONSE OF ASTHMA PATIENTS TO THE SINGLE INJECTION OF CORTICOTROPHIN The effect on the PEFR of these patients after the injection was striking. The change in PEFR was significantly different from the pre-injection reading at 6,12 , 24,48 , and 72 hours ( $P<0.001$ at all times) in the 12 patients who responded. After the initial response of the bronchospasm to one injection lasting up to 72 hours or more, five of the 12 patients required only one further injection of 200 i.u. of corticotrophin before discharge from hospital, without steroid therapy in any form. Seven needed more prolonged corticotrophin after the initial relief from the high dose level and were controlled using 80 i.u. every second or third day.

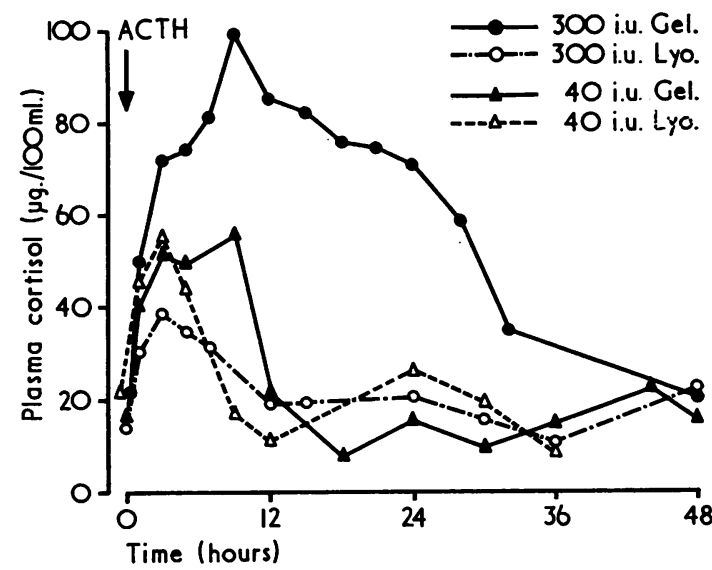

FIG. 4. Plasma 11-OHCS response to 40 i.u. and 300 i.u. of corticotrophin in gelatin and lyophilized porcine corticotrophin in a normal subject.

Arrangements were made for the corticotrophin to be given to the patients at home when the dose was reduced to the minimum level required to control symptoms. Where the patient proved reluctant or unable to administer the corticotrophin to himself, the help of the general practitioner or district nurse was enlisted. The patient who did not respond to corticotrophin in high dosage was given prednisone, $60 \mathrm{mg}$. daily, over a period of two weeks. He experienced some subjective relief but never obtained a PEFR of more than $250 \mathrm{1}$./minute. Though the onset and course of the asthma in this patient was no different from that of the usual intrinsic asthmatic, he seemed to have irreversible airways obstruction. 
An extrinsic asthmatic boy of 16 who had had over 40 hospital admissions for asthma and had been on long-term prednisone for many years, was weaned off the steroids during an exacerbation, when higher doses of prednisone failed to produce a remission. Following on the initial reactivation of his adrenal glands by daily corticotrophin, the following investigation was performed. He was given injections of corticotrophin in gelatin in doses ranging from 40 to 200 i.u. At each dose level the plasma 11-OHCS and the forced expiratory volume in one second $\left(\mathrm{FEV}_{1}\right)$ were measured at $0,1,3,5,7,9,12,24,28,32,36,48$, 72 and 96 hours. The bronchospasm was relieved after each injection as shown by clinical assessment and a rise in FEV $_{1}$ values for a period of up to five days. In each test, the pre-injection level of plasma 11-OHCS was reached in the time expected from the earlier data obtained in this study (see Fig. 3), being longest 48 hours after 200 i.u. It was evident that the effect of each injection in terms of the relief of bronchospasm lasted longer than the rise of the plasma 11-OHCS induced by the corticotrophin.

\section{DISCUSSION}

We think the most suitable preparation of corticotrophin for prolonged use is one which has a duration of activity, in terms of plasma cortisol elevation, of 15 to 18 hours. This duration of endogenous corticotrophin suppression allows for some degree of recovery of the hypothalamicpituitary axis and production of endogenous corticotrophin between each injection maintaining the 24-hour diurnal rhythm even if administered on a daily basis (Friedman and Greenwood, 1968 ; Friedman, 1968). The duration of beneficial therapeutic activity of corticotrophin frequently persists for many hours after the plasma 11-OHCS levels have returned to baseline values.

The majority of patients requiring prolonged corticotrophin therapy are well controlled on three injections a week of 20 or 40 i.u. of a gelatin preparation which elevates the plasma cortisol level for 15 to 18 hours. At times, if an exacerbation or relapse of the condition occurs, the injections may have to be increased to one daily. A preparation which maintains the diurnal rhythm would appear on theoretical grounds to be more physiological than one with a longer duration which abolishes the diurnal rhythm. A preparation which stimulates the adrenal gland for 15 to 18 hours allows for the planning of a therapeutic regime based on a 24-hour unit time interval; this has proved to be satisfactory in practice? During an acute exacerbation of asthma, during which an increased amount of corticotrophin indicated, we think it better to produce a sustaine maximal adrenal stimulus for longer than that achieved by 40 i.u. of corticotrophin gel. Thiog would eliminate the decline in the plasma steroid levels in between each injection (see Fig. 1) and presumably provide a higher level of cortisol to the tissues.

Corticotrophin is rapidly destroyed in the bloodstream by circulating enzymes, and most oif it is inactivated before actually stimulating the adrenal gland. Several substances which delay release or destruction at the site of the injectio $\vec{n}$ have been added to corticotrophin in order to prolong its duration of action. Prolonged adrenocortical stimulation can be achieved either bæ increasing the dose of corticotrophin or by alter ing the nature of the carrier vehicle. There musto however, be a point at which further increases io the dose of corticotrophin administered will not produce increased steroidogenesis. The maximun increment of plasma 11-OHCS rises with increas ing doses of corticotrophin up to 200 i.u., but do not seem to be accompanied by a further increase in response. A tenfold increase in corticotrophin from 40 to 400 i.u. raises the maximal respons by only $50 \%$. The limiting factor in the response must be the maximum capacity of the adren gland to put out cortisol, and the availability of corticotrophin.

Sensitivity to corticotrophin varies from ind vidual to individual (Bayliss and Steinbeck, 1954) In the present study, this difficulty has bee partially overcome whenever possible by evaluo ating the effect of two or more dosages of corticos trophin on the same subject and comparing the difference in response. Cameron and Kilbor (1964), using an intravenous infusion of cortices trophin, measured the plasma contisol response if normal subjects. The variation of the respons was found to be confined to within fairly narrow limits. In our study, at all dose levels, the findings confirm this observation but the duration of response to 400 i.u. in one subject was shorter than expected, while in another the response 80 i.u. was unexpectedly long. Where a particulas dose was given to the same subject on more than one occasion, the response obtained was fairly consistent, in regard to both duration and max mum intensity of the stimulus. An exception to this is the long duration of activity obtained ia one subject with 80 i.u. The effect of the same quantity of corticotrophin suspended in different amounts of gelatin did not produce any significan 
difference in either duration or intensity of adrenocortical stimulation. The amount of gelatin does not appear to affect the rate of inactivation of corticotrophin at the site of the injection. Lyophilized conticotrophin was rapidly destroyed. The stimulus of 300 i.u. given intramuscularly was less effective in intensity and duration of adrenal stimulation than 40 i.u. of corticotrophin in gelatin.

Our conclusions from these studies are that in order to achieve prolonged and continuous adrenal stimulation for a short period of time, the optimum dose of corticotrophin is 200 i.u. which can be suspended in $1 \mathrm{ml}$. of gelatin for ease of administration, and should probably be given every 36 hours.

The administration of a large single dose of corticotrophin to asthmatic patients with exacerbations severe enough to warrant hospital admission, but not so severe as to be classified as status asthmaticus, was sufficient to induce subjective and objective relief within 72 hours in 12 of the 13 patients so treated. Improvement in the PEFR was recorded in all but one patient by 6 hours after the injection. The high dose of corticotrophin was used in these patients instead of the usual short-term high-dosage exogenous steroids, since this has the advantage of administration by injection which reduced considerably the possibility of the patient continuing with steroid therapy for a long period of time. Repeated injections of the high-dose corticotrophin may be administered should relapse occur after the first injection. Clinical assessment and PEFR measurements will determine the necessity for further corticotrophin therapy.

The beneficial therapeutic effect of corticotrophin often persists for many hours after the plasma levels of cortisol have returned to the baseline value. The exact site of action of glucocorticoids is as yet unknown with certainty (Schayer, 1964; Houck and Patel, 1965). If the patient relapses after the initial injections and has such severe bronchospasm that prolonged steroid therapy is deemed necessary, then we think that long-term treatment with corticotrophin is superior to corticosteroid treatment, in children because of its effect on growth (Friedman and Strang, 1966) and in all age groups because of the difference in the effect of long-term corticosteroids and corticotrophin therapy on the hypothalamic-pituitary-adrenal axis (Friedman and Greenwood, 1968 ; Friedman, 1968).

A number of investigations have shown a decrease in urinary 17 -ketosteroid excretion in asthmatic patients (Rackemann, 1945 ; ErikssonLihr, Forssell, Pettay, and Rusk, 1949). However, Mustafá, Jiménez Diaz, and Vivanco (1960) and Kass and Appleby (1960) found no difference in the amounts of 17-hydroxycorticosteroids excreted in the urine of asthmatic patients and normal controls, before and after corticotrophin. Robson and Kilborn (1965) found a diminished response of plasma 11-OHCS following corticotrophin stimulation in a proportion of their asthmatics tested but Nelson, Mackay, Sheridan, and Weaver (1966) were unable to demonstrate any difference in adrenocortical response between asthmatics and normal controls following administration of corticotrophin. Kilborn and Robson (1965), Nelson et al. (1966), and the present study show that corticotrophin is effective in the control of asthma.

There may be a place for administering corticotrophin continuously by an intravenous drip. We have not investigated this procedure but think there is no great advantage in this form of administration over that produced by injecting a large quantity of corticotrophin suspended in gelatin which slowly releases the corticotrophin over a number of hours, though it would avoid the injection of gelatin.

Prolonged steroid administration leads to functional (Stoner and Whiteley, 1954) and anatomical (Sasano and Kitagawa, 1964) atrophy of the adrenal gland. Corticotrophin therapy should, therefore, not be used in patients with an exacerbation of asthma who have already had prolonged steroids without prior reactivation of the adrenal by corticotrophin. Unless this is done, the corticotrophin administered is unlikely to stimulate steroidogenesis.

Finally, we wish to stress that the patients who responded to the high-dosage corticotrophin were severe asthmatics but not in status asthmaticus. The latter condition is one which may lead to sudden death and it could be dangerous to withhold corticosteroids in its management.

We are grateful to Sir Kenneth Robson, Dr. J. Smart, and Dr. F. H. Scadding, physicians at Brompton Hospital, for allowing us to study patients under their care.

\section{REFERENCES}

Bayliss, R. I. S., and Steinbeck, A. W. (1954). The adrenal response to corticotrophin: the effect of ACTH on plasma adrenal steroid levels. Brit. med. J., 1, 486.

Black, S., and Friedman, M. (1965). Adrenal function and the inhibition of allergic responses under hypnosis. Ibid., 1, 562.

Cameron, E. A., and Kilborn, J. R. (1964). Plasma cortisol and corticosterone response to infused corticotrophin in normal subjects. Clin. chim. Acta, 10, 308.

Engel, F. L. (1961). Extra-adrenal actions of adrenocorticotropin. Vitam. and Horm., 19, 189. 
Eriksson-Lihr, Z., Forssell, P., Pettay, O., and Rusk, I. (1949). Investigations of the function of the suprarenal cortex in allergic diseases. Acta Allerg. (Kbh.), 2, 299.

Farrell, G. L., and Lamus, B. (1953). Steroids in adrenal venous blood of the dog. Proc. Soc. exp. Biol. (N.Y.), 84, 89.

Friedman, M. (1968). The effect of corticotrophin on hypothalamicpituitary-adrenal function of children. Proc. roy. Soc. Med. 61, 291.

- and Greenwood, F. C. (1968). The Investigation of Hypothalamicpituitary-adrenal Function, ed. James, V. H. T., and Landon, J. University Press, Cambridge.

- - and Strang, L. B. (1966). The effect of long-term corticosteroids and corticotrophin on the growth of children. Lancet, 2, 568 .

Houck, J. C., and Patel, Y. M. (1965). Proposed mode of action of corticosteroids on the connective tissue. Nature (Lond.), 206, 158

Kass, I., and Appleby, S. (1960). The status of the adrenal gland in the asthmatic patient. Amer. J. med. Sci., 240, 213.

Kilborn, J. R., and Robson, A. O. (1965). The effect of corticosteroid and corticotrophin therapy on adrenocortical function in bronchial asthma. Thorax, $20,422$.
Mattingly, D. (1962). A simple fluorimetric method for the esti- $\bar{F}$ mation of free 11-hydroxycorticoids in human plasma. J clin. Path., 15, 374 .

Mustafá, O. S., Jiménez Diaz, C., and Vivanco, F. (1960). The state of the adrenocortical function in bronchial asthma. Bull. Inst. med. Res. (Madr.), 13, 25.

Nabarro, J. D. N. (1960). The pituitary and adrenal cortex in general medicine. Brit. med. J., 2, 553 .

Nelson, J. K., Mackay, J. S., Sheridan, B., and Weaver, J. A. (1966). ڤึ Intermittent therapy with corticotrophin. Lancet, 2, 78.

Rackemann, F. M. (1945). Depletion in asthma. J. Allergy, 16, 136.

Robson, A. O., and Kilborn, J. R. (1965). Studies of adrenocortical function in continuous asthma. Thorax, 20, 93.

Sasano, N., and Kitagawa, I. (1964). Corticosteroid-induced atrophy of the human adrenals comparable to panhypopituitarism. Tohoku J. exp. Med., 83, 270.

Schayer, R. W. (1964). A unified theory of glucocorticoid action. Perspect. Biol. Med., 8, 71 .

Stoner, H. B., and Whiteley, H. J. (1954). The effects of cortisone and corticotrophin on the human adrenal cortex. Lancet, $2,992$. 